\title{
Characteristics, onset, and evolution of neurological symptoms in patients with COVID-19
}

\author{
Imen Kacem ${ }^{1,2} \cdot$ Alya Gharbi $^{1,2} \cdot$ Chahida Harizi $^{2,3} \cdot$ Emira Souissi $^{1,2} \cdot$ Mouna Safer $^{2,4} \cdot$ Amina Nasri $^{1,2} \cdot$ Hajer Letaief $^{2,4}$. \\ Manel Akkari ${ }^{1,2}$. Aicha Hechaichi ${ }^{2,4}$. Saloua Mrabet ${ }^{1,2}$. Sonia Dhaouadi ${ }^{2,4}$ - Mouna Ben Djebara ${ }^{1,2}$. \\ Sondes Derouiche ${ }^{2,4} \cdot$ Amina Gargouri $^{1,2} \cdot$ Mohamed Chahed $^{2,5} \cdot$ Nissaf Ben Alaya $^{2,4} \cdot$ Riadh Gouider $^{1,2}$ (1)
}

Received: 27 August 2020 / Accepted: 27 October 2020 / Published online: 17 November 2020

(C) Fondazione Società Italiana di Neurologia 2020

\begin{abstract}
Background A wide range of neurological manifestations has been described in COVID-19.

Methods In this nationwide retrospective observational study, patients in Tunisia diagnosed with COVID-19 between the 2nd of March and the 16th of May 2020 were contacted by telephone. We collected demographic and clinical data and specified characteristics and evolution of main neurological symptoms.

Results Of 1034 confirmed COVID-19 patients, 646 were included (mean age 42.17 years old) and 466 (72.1\%) had neurological symptoms. Neurological symptoms were isolated $22.7 \%(n=106)$. Headache was the most frequent neurological symptom $(n=279,41.1 \%)$ : mainly frontotemporal $(n=143,51.1 \%)$ and mild or moderate $(n=165,59.1 \%)$. When associated with fever $(n$ $=143,51.3 \%$ ), headache was more likely to be severe and present at onset. Recovery was reported in $83.2 \%$. Smell and taste impairment were found in 37.9\% $(n=245)$ and 36.8\% $(n=238)$ respectively. Among them, $65.3 \%(156 / 239)$ were anosmic and $63.2 \%$ (146/231) were ageusic. A complete improvement was found in $72.1 \%(174 / 240)$ of smell impairment and in $76.8 \%(179 /$ $233)$ of taste impairment. Myalgia $(n=241,37.3 \%)$ and sleep disturbances $(n=241,37.3 \%)$ were also frequent. Imported cases had more neurological symptoms ( $p=0.001$ ). In $14.5 \%$, neurological symptoms preceded the respiratory signs (RS). RS were associated with more frequent $(p=0.006)$ and numerous $(p<0.001)$ neurological symptoms.

Conclusions Neurological symptoms in COVID-19 are frequent, can be isolated and present at onset. A total recovery is the most recorded outcome. RS are predictive of neurological symptoms. Studies in to virus and host genetics should be considered to understand the different phenotypes.
\end{abstract}

Keywords COVID-19 $\cdot$ SARS-CoV-2 $\cdot$ Neurological $\cdot$ Symptoms/manifestations $\cdot$ Tunisia

Riadh Gouider

riadh.gouider@gnet.tn

1 Department of Neurology, LR18SP03, Clinical Investigation Center of Neurosciences and Mental Health, Universitary Hospital Razi-Mannouba, Tunis, Tunisia

2 Faculty of Medicine of Tunis, University of Tunis El Manar, Tunis, Tunisia

3 Department of Epidemiology and Statistics, Abderrahman Mami Hospital, Ariana, Tunisia

4 National Observatory of New and Emerging Diseases of Tunisia, Tunis, Tunisia

5 Department of Epidemiology and Public Health, Faculty of Medicine of Tunis, University of Tunis El Manar, Tunis, Tunisia

\section{Introduction}

The coronavirus disease of 2019 (COVID-19), caused by the 2019 novel coronavirus SARS-CoV-2 [1], emerged in December 2019 in Wuhan, China, and rapidly spread to more than 200 countries [2]. The first confirmed imported case in Tunisia (a Tunisian returning from Italy [3]) was identified on 2nd March 2020.The first locally infected cases were diagnosed on 9th March, 2020, indicating clear horizontal transmission. The whole SARS-CoV-2 genome sequencing of two Tunisian patients reveals a genotype similar to the European and American strains [4, 5]. As of August 2020, 3206 patients have been diagnosed with COVID-19 in Tunisia representing 27.1 cases per 100,000 habitants (www.covid-19.tn).

The most frequent clinical features of COVID-19 are fever, cough, and dyspnea, as seen in a hospitalized cohort in 
Tunisia [6]. However, a wide range of neurological manifestations has been described as headache, encephalitis, stroke, dizziness, confusion, myalgia, anosmia, or ageusia [7]. Several neuropathophysiological hypotheses were discussed including direct and indirect mechanisms [8]. Previous studies were focused on hospitalized COVID-19 patients and very few included all people exposed to COVID-19 whether symptomatic or not.

To date, few studies described the characteristics of COVID-19 neurological symptoms and their evolution [9, $10]$.

In this paper, we describe the neurological symptoms associated with COVID-19, their main characteristics, and their evolution in the Tunisian population followed by discussion of their underlying pathophysiological mechanisms.

\section{Method}

\section{Study design}

We conducted a nationwide retrospective observational study on COVID-19 patients in Tunisia diagnosed between the 2nd of March 2020 and the 15th of May 2020. The diagnosis was made by real-time reverse-transcription polymerase chain reaction (RT-PCR) analysis of nasal and throat swab specimens. Patients of the electronic database of the National Observatory of New and Emerging Diseases of Tunisia (ONMNE) were contacted by a team of trained neurologists between 27 th April, 2020, and 16th May, 2020. During the telephone interview, patients underwent a survey questionnaire validated by the neurologists of the Department of Neurology and the Clinical Investigation Centre of Neurosciences and Mental Health of Razi Hospital. For deceased patients, we interviewed close family members.

Patients with insufficient data and no contact phone number were not included. Patients who were not reachable or did not consent were excluded.

\section{Data collection}

The following demographic and general clinical data were collected through the questionnaire:

- Sex, date of birth, age, and current location (domicile, place/structure of containment, hospital)

- Personal history of neurological disease

- Date of disease onset defined as date of onset of any symptoms for symptomatic patients and date of first positive RT-PCR for asymptomatic patients

- Mode of transmission: imported cases which were diagnosed upon arrival from foreign countries and patients that were infected locally.
- Possible need of hospitalization

- Extra-neurological symptoms: fever, cough, dyspnea, and gastrointestinal symptoms

- Neurological symptoms: headache, disorientation, behavior disorders, dizziness, sleep disturbances, cognitive complaint, seizures, focal weakness, smell impairment, taste impairment, myalgia, paresthesia or neuropathic pain, and visual loss/blurred vision.

The presence of respiratory symptoms (RS) was defined as the presence of dyspnea and/or cough.

We specified the chronology between onset of neurological symptoms and RS when possible.

For headache, smell impairment, taste impairment, myalgia, and sleep disturbances, a specific detailed questionnaire was used including onset time, duration, and characteristics of each symptom. When patients did not remember the details of these symptoms, they were not considered for the percentage evaluation. Sense of smell and taste were assessed using a subjective score ranging from 0 to $10(0=$ no sense of smell or taste, $10=$ normal sense of smell or taste). This was assessed for before disease onset, during the disease and after recovery.

\section{Statistical analysis}

All statistical analyses were performed using SPSS 24.0.0 (IBM SPSS Statistics Version 24). Mean and standard deviations (SD) or median and interquantile range (IQR) were used for continuous variables when appropriate. Categorical variables were expressed as counts and percentages.

A chi-square or Fisher's exact test was used to calculate differences in categorical data as appropriate. To analyze the continuous variables, Mann-Whitney $U$ test or $t$ test was conducted according to the distribution of data. The significance level was set at $p<0.05$

A logistic regression was used to explore the risk factors associated with the neurological symptoms. Variables with univariate analysis test value $\leq 0.2$ were entered into logistic multivariate regression models. The final returned variables were those significant at the level of $5 \%$. Odds ratio (OR) was presented with $95 \%$ confidence intervals (CI).

\section{Standard protocol approvals, registration and patients consents}

The research protocol was approved by the local ethic committee board of Razi Hospital on the 27th of April 2020. Verbal consent to participate was obtained from all patients or their legal proxy. 


\section{Results}

\section{Demographic and Clinical Data}

Among 1034 SARS-Cov-2 infected cases, a total of 646 confirmed COVID-19 patients were included in the analysis. One hundred sixty-five were imported cases and 480 were locally transmitted cases. Mode of transmission was not specified in one case. Eighty-eight patients required hospitalization. At the time of survey, 332 were housebound, 145 within containment quarantine and 15 in hospital. Participants' location was not specified in 154 cases. The demographic and clinical characteristics are presented in Table 1.The mean age was $42.17 \pm 17.58$ years old. Sex ratio was 0.85 . Fifty-nine patients had a medical history inclusive of a neurological disease prior to COVID-19 infection. Fever (35.3\%) and cough $(36.2 \%)$ were the most frequent extra-neurological symptoms.

\section{Neurological symptoms}

Neurological symptoms were found in $72.1 \%$ of the cases. They preceded RS in $14.5 \%$ of cases, were concomitant to RS in $48.1 \%$, and followed them in $27.8 \%$. One hundred six

Table 1 Demographic and clinical data of COVID-19 patients according to mode of transmission, age, and respiratory signs

\begin{tabular}{|c|c|c|c|c|c|c|c|c|c|c|}
\hline & \multirow[t]{2}{*}{ Total } & \multicolumn{3}{|c|}{ Mode of transmission } & \multicolumn{3}{|l|}{ Age } & \multicolumn{3}{|c|}{ Respiratory symptoms (RS) } \\
\hline & & $\begin{array}{l}\text { Imported } \\
n=165\end{array}$ & $\begin{array}{l}\text { Local } \\
n=480\end{array}$ & $p$ value & $\begin{array}{l}<50 \text { years } \\
n=400\end{array}$ & $\begin{array}{l}>50 \text { years } \\
n=226\end{array}$ & $p$ value & $\begin{array}{l}\mathrm{RS}+ \\
n=268\end{array}$ & $\begin{array}{l}\mathrm{RS}- \\
n=378\end{array}$ & $p$ value \\
\hline $\begin{array}{l}\text { Age }(\text { mean }(\mathrm{SD}), \\
\text { years) }\end{array}$ & $42.17 \pm 17.58$ & $44.2 \pm 14.9$ & $41.5 \pm 18.4$ & 0.059 & $31.3 \pm 11.9$ & $59.3 \pm 8.8$ & 0.000 & $44.0 \pm 16.7$ & $40.8 \pm 18.1$ & 0.22 \\
\hline \multirow[t]{2}{*}{$\operatorname{Sex}(n(\%))$ - Male } & $348(53.9)$ & $83(50.3)$ & $263(55.0)$ & 0.295 & $225(56.4)$ & $114(50.4)$ & 0.152 & $144(53.9)$ & $203(53.8)$ & 0.983 \\
\hline & $298(46.1)$ & $82(49.7)$ & $215(45.0)$ & & $174(43.6)$ & $112(49.6)$ & & $123(46.1)$ & $174(46.2)$ & \\
\hline \multicolumn{11}{|c|}{ Extra-neurological symptoms $(n(\%))$} \\
\hline - Fever & $228(35.3)$ & $64(38.8)$ & $164(35.3)$ & 0.284 & $138(34.5)$ & $88(38.9)$ & 0.267 & $148(55.2)$ & $80(21.2)$ & $<0.001$ \\
\hline - Cough & $234(36.2)$ & $62(37.6)$ & $172(35.8)$ & 0.688 & $142(35.5)$ & $86(38.1)$ & 0.524 & $234(87.3)$ & 0 & $<0.001$ \\
\hline - Dyspnea & $118(18.3)$ & $27(16.4)$ & $91(19)$ & 0.457 & $65(16.3)$ & $52(23.0)$ & 0.037 & $118(44)$ & 0 & $<0.001$ \\
\hline $\begin{array}{l}\text { - Gastrointestinal } \\
\text { symptoms }\end{array}$ & $213(33.0)$ & $52(31.5)$ & $161(33.5)$ & 0.633 & $121(30.3)$ & $87(38.5)$ & 0.035 & $152(56.7)$ & $61(16.1)$ & $<0.001$ \\
\hline $\begin{array}{l}\text { Neurological } \\
\text { symptoms ( } n(\%), \\
\text { any) }\end{array}$ & $466(72.1)$ & $135(81.8)$ & $331(71.0)$ & 0.001 & $283(70.8)$ & $167(73.9)$ & 0.401 & $235(87.7)$ & $231(61.1)$ & $<0.001$ \\
\hline - Headache & $279(41.1)$ & $76(46.1)$ & $204(42.5)$ & 0.426 & $168(42.0)$ & $103(52.6)$ & 0.386 & $158(59.0)$ & $122(32.3)$ & $<0.001$ \\
\hline - Smell impairment & 245 (37.9) & $84(50.9)$ & $161(33.5)$ & $<0.001$ & $157(39.3)$ & $80(35.4)$ & 0.534 & $128(47.8)$ & $117(31.0)$ & $<0.001$ \\
\hline - Taste impairment & $238(36.8)$ & $84(50.9)$ & $154(32.1)$ & $<0.001$ & $144(36)$ & $87(38.5)$ & 0.657 & $130(48.5)$ & $108(28.6)$ & $<0.001$ \\
\hline - Myalgia & $241(37.3)$ & $80(48.5)$ & $161(33.5)$ & 0.001 & $150(37.5)$ & $82(36.3)$ & 0.762 & $131(54.4)$ & $110(45.6)$ & $<0.001$ \\
\hline - Sleep disturbance & $241(37.3)$ & $67(40.6)$ & $174(36.3)$ & 0.318 & $154(38.5)$ & $81(35.8)$ & 0.509 & $123(45.9)$ & $118(31.2)$ & $<0.001$ \\
\hline $\begin{array}{l}\text { - Visual loss/blurred } \\
\text { vision }\end{array}$ & $48(7.4)$ & $15(9.1)$ & $33(6.9)$ & 0.349 & $28(7.0)$ & $18(8.0)$ & 0.340 & $31(11.6)$ & $17(4.5)$ & 0.001 \\
\hline - Focal weakness & $16(2.5)$ & $3(1.8)$ & $13(2.7)$ & 0.772 & $7(1.8)$ & $7(3.1)$ & 0.274 & $10(3.7)$ & $6(1.6)$ & 0.084 \\
\hline - Disorientation & $13(2.0)$ & $6(3.6)$ & $7(1.5)$ & 0.107 & $6(1.5)$ & $6(2.7)$ & 0.367 & $11(4.1)$ & $2(0.5)$ & 0.001 \\
\hline - Behavior disorders & $13(2.0)$ & $2(1.2)$ & $11(2.3)$ & 0.530 & $8(2.0)$ & $4(1.8)$ & 1.000 & $10(3.7)$ & $2(0.5)$ & 0.005 \\
\hline \multicolumn{11}{|c|}{ Time to appearance (median (IQR), $d$ ): } \\
\hline - Headache & $1(0-3)$ & $1(0-3)$ & $1(0-3)$ & 0.363 & $1(0-3)$ & $1(0-2)$ & 0.488 & $1(1-3)$ & $1(0-2)$ & 0.067 \\
\hline - Myalgia & $1(0.5-3)$ & $1(0.75-3)$ & $1(1-3)$ & 0.920 & $1(0.25-3)$ & $1(1-3)$ & 0.971 & $1(1-3)$ & $1(0.5-3)$ & 0.927 \\
\hline - Smell impairment & $2.5(1-5)$ & $3(1-5)$ & $2(1-5)$ & 0.044 & $3(1-5)$ & $2(1-4)$ & 0.045 & $2(1-5)$ & $3(1-5)$ & 0.427 \\
\hline - Taste impairment & $3(1-5)$ & $3(1-4)$ & $2(1-5)$ & 0.889 & $3(1-5)$ & $2(1-4)$ & 0.435 & $2(1-5)$ & $3(1-4)$ & 0.814 \\
\hline \multicolumn{11}{|c|}{ Total duration (median (IQR), $d$ ): } \\
\hline - Headache & $4(2-7)$ & $4.5(3-7.5)$ & $4(2-7)$ & 0.586 & $4(2-7)$ & $4(3-7)$ & 0.607 & $4.75(3-7)$ & $3(2-7)$ & 0.082 \\
\hline - Myalgia & $5(3-10)$ & $5(2-8.5)$ & $5(3-10)$ & 0.244 & $5(2-7)$ & $6(3-10)$ & 0.106 & $5(3-10)$ & $4(3-8)$ & 0.818 \\
\hline - Smell impairment & $7(4.5-14)$ & $7(4.38-14)$ & $7(4-14)$ & 0.911 & $7(4-14)$ & $7(4.5-14)$ & 0.902 & $8(5-15)$ & $7(4-12)$ & 0.223 \\
\hline - Taste impairment & $7(4-14)$ & $7(4-10)$ & $7(4-10)$ & 0.591 & $7(4-14)$ & $7(4-14)$ & 0.232 & $8(5-14)$ & $7(3.25-10)$ & 0.184 \\
\hline - Sleep disorders & $7(4-15)$ & $14.5(14-15)$ & $7(3.25-15)$ & 0.020 & $7(3-15)$ & $14(7-17.5)$ & 0.437 & $14(4-15)$ & $7(4-15)$ & 0.779 \\
\hline
\end{tabular}

Significant results have been italicized 
patients $(22.7 \%)$ of the patients had purely neurological symptoms only.

Headache was the most common reported symptoms found in $41.1 \%$ of the cases. The pain was most commonly located in the frontotemporal region $(51.2 \%)$. It was mostly mild or moderate $(59.1 \%)$. The median time between the appearance of the first COVID-19 symptoms and the onset of headache was 1 day. Headache appeared during the first 3 days of the disease in $62.3 \%$. The median duration of headaches was 4 days and median attack duration $3 \mathrm{~h}$ (range: $15 \mathrm{~min}$ to $24 \mathrm{~h}$ ). A complete recovery was reported in $83.2 \%$. When associated with fever $(51.3 \%)$, headache was more likely severe or present at onset (Table 2).

Smell and taste impairment was reported in $37.9 \%(n=$ $245)$ and $36.8 \%(n=238)$ of cases respectively. Among patients with smell impairment, 65.3\% (156/239) had complete anosmia, 62 patients $(26.6 \%)$ mentioned parosmia, and 26 patients $(10.9 \%)$ olfactory hallucinations. Only 93 patients (38.4\%) reported concomitant nasal obstruction. Fifty-nine (24.9\%) reported a fluctuating hyposmia. Among patients with taste impairment, 63.2\% (146/231) reported a complete ageusia, 162 participants $(79.4 \%)$ had an altered taste of sweetness, $163(79.9 \%)$ had an altered taste of saltiness, 145 (71.4\%) had an altered acid taste, and 128 (66\%) had an altered taste of bitterness. Two hundred three patients reported combined smell and taste impairment, 42 reported smell impairment only, and 35 reported taste impairment only. The median time from the disease onset to development of smell and taste impairment was two and a half days (IQR 1.0-5.0) and 3 days (IQR 1.0-5.0) respectively. The median duration of smell and taste impairment was 7 days (smell impairment IQR 4.5-14.0; taste impairment IQR 4.0-14.0). A complete recovery was noted in $72.1 \%(174 / 240)$ of smell impairment and $76.8 \%$ (179/233) of taste impairment. Chemosensory impairment scores are presented in Fig. 1.

Myalgia was reported in $37.3 \%$ of the cases. Muscle pain was distributed as follows: generalized ( $n=95 ; 43.2 \%)$, limbs $(n=68 ; 30.5 \%)$, trunk $(n=30 ; 13.6 \%)$, and limb and trunk $(n$ $=28 ; 12.7 \%$ ). Muscle cramps were present in $12.4 \%$ of cases. The median time from the disease onset to appearance of myalgia was 1 day (IQR 0.5-3.0) and the median duration was 5 days (IQR 3.0-10.0).

More than one-third of the patients (37.3\%) had sleep disturbances. The median daily sleep duration was $6 \mathrm{~h}$ (range: 1.5-20 h). Sleep disturbances included insomnia ( $n=123$; $51.0 \%$ ), hypersomnia ( $n=40 ; 16.6 \%)$, and day-night cycle reversal $(n=30 ; 12.4 \%)$. Participant-reported causes of insomnia included the following: anxiety (35.0\%), RS $(13.8 \%)$, fever $(9.8 \%)$, and pain $(9.8 \%)$. The median total sleep disturbance duration was 7 days (IQR 4.0-15.0).

The other neurological symptoms were the following: visual loss/blurred vision $(n=48)$, focal weakness $(n=16)$, disorientation $(n=13)$, behavior disorders $(n=13)$, dizziness $(n=11)$, paresthesia/neuropathic pain $(n=10)$, cognitive complaint $(n=5)$, and seizures $(n=1)$.
Table 2 Headache characteristics in patients with COVID-19 in Tunisia

\begin{tabular}{lllll}
\hline & Total & With fever & Without fever & $p$ value \\
\hline & $n=279$ & $n=143(51.3 \%)$ & $n=136(48.7 \%)$ & \\
Time to appearance (median (IQR), days) & $1(0-3)$ & $1(0-2)$ & $1(0-4)$ & 0.127 \\
Total duration (median (IQR), days) & $4(2-7)$ & $4.25(2.25-7)$ & $3.5(2-7)$ & 0.202 \\
Attack duration (median (IQR), hours) & $3(1-12)$ & $4(2-24)$ & $2(1-12)$ & 0.071 \\
Headache at onset $(n(\%))$ & $219(78.5)$ & $122(85.3)$ & $97(71.3)$ & 0.004 \\
Location $(n(\%))$ & & & & \\
- Frontal & $124(44.4)$ & $67(46.9)$ & $57(41.9)$ & \\
- Generalized & $80(28.7)$ & $39(27.3)$ & $41(30.1)$ & \\
- Bitemporal & $19(6.8)$ & $10(7.0)$ & $9(6.6)$ & $11(8.1)$ \\
- Occipital & $20(7.2)$ & $9(6.3)$ & $8(5.9)$ & \\
- Unilateral & $16(5.7)$ & $8(5.6)$ & $7(5.1)$ & \\
- Variable & $13(4.7)$ & $6(4.2)$ & $3(2.2)$ & \\
- Not specified & $7(2.5)$ & $4(2.8)$ & & \\
Intensity $(n(\%))$ & & & $91(66.9)$ & 0.026 \\
- Mild or moderate & $165(59.1)$ & $74(51.7)$ & $43(31.6)$ & 0.005 \\
- Severe & $110(39.4)$ & $67(46.9)$ & $2(1.5)$ & 0.404 \\
- Not specified & $4(1.4)$ & $2(1.4)$ & $21(15.4)$ & 0.199 \\
Persistence of headache after recovery $(n(\%))$ & $47(16.8)$ & $26(18.2)$ & $5(3.7)$ & \\
Consultation for headache $(n(\%))$ & $15(5.4)$ & $10(7.0)$ & \\
\hline
\end{tabular}

Significant results have been italicized 


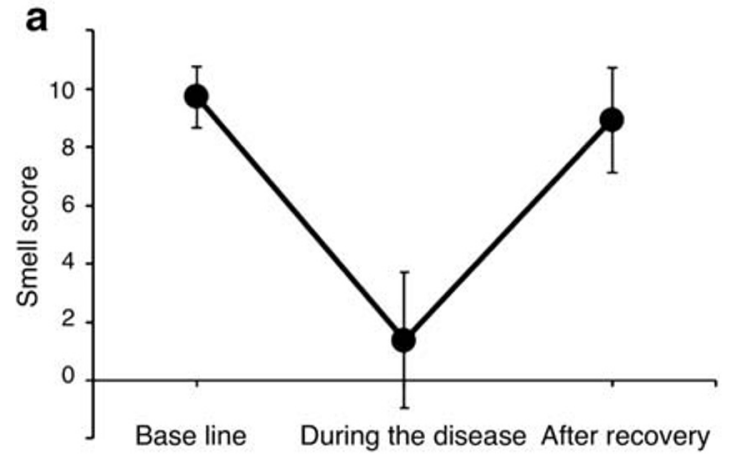

Fig. 1 Chemosensory score impairment (mean, SD) in patients with COVID-19 in Tunisia (a smell impairment, b taste impairment)

Considering the four main neurological symptoms (headache, smell impairment, taste impairment, and myalgia), 115 patients had only one symptom (17.8\%), 140 had two symptoms (21.7\%), 110 had three symptoms (17.0\%), and 69 had all four symptoms (10.7\%).

\section{Association between hospitalization and neurological symptoms}

Patients who required hospitalization were older (51.82 \pm 17.46 years old) than non-hospitalized $(\mathrm{NH})$ patients $(40.66$ \pm 17.13 years old) with no significant differences between the 2 groups. Hospitalized patients $(\mathrm{H})$ had a higher frequency of any neurological signs $(H=76.1 \%, \mathrm{NH}=71.5 \%, p=0.368)$, headache $(H=48.9 \% ; \mathrm{NH}=42.1 \%, p=0.071)$, myalgia $(H=$ $46.6 \%, \mathrm{NH}=35.8 \%, p=0.035)$, sleep disturbance $(H=$ $44.3 \%$; $\mathrm{NH}=36.2 \%, p=0.090)$, visual loss/blurred vision $(H=13.6 \% ; \mathrm{NH}=6.5 \%, p=0.020)$, focal weakness $(H=$ $3.4 \% ; \mathrm{NH}=2.3 \%, p=0.375)$, disorientation $(H=6.8 \% ; \mathrm{NH}=$ $1.3 \%, p=0.004)$, and behavior disorders $(H=3.4 \%$; $\mathrm{NH}=$ $1.8 \%, p=0.225)$. NH patients had a higher prevalence of smell impairment $(H=27.3 \%, \mathrm{NH}=39.6 \%, p=0.017)$ and taste impairment $(H=31.8 \%, \mathrm{NH}=37.6 \%, p=0.176)$.

\section{Association between neurological symptoms and age, transmission mode, and extra-neurological signs}

- Participants infected abroad had a higher prevalence of neurological symptoms than those infected locally. There was a particularly prevalence of smell impairment $(p<$ $0.001)$, taste impairment $(p<0.001)$, and a longer sleep disturbance duration $(p=0.02)$ in those infected abroad (Table 1).

- There was no difference in the frequency of the neurological symptoms between the two age groups (Table 1).

- Patients with RS were more likely to have fever $(p<$ $0.001)$, gastrointestinal symptoms $(p<0.001)$, and neurological symptoms $(p<0.001)$ (Table 1$)$.

- Conversely, the frequency of RS was higher in patients who reported the 4 main neurological symptoms:

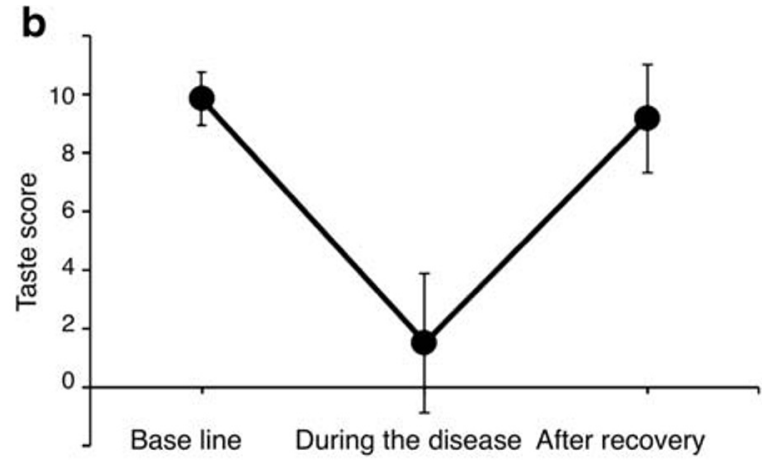

headache (with $\mathrm{RS}=56.7 \%$, without $\mathrm{RS}=43.3 \% ; p<$ 0.001 ), anosmia (with $\mathrm{RS}=52.2 \%$, without $\mathrm{RS}=47.8 \%$; $p<0.001$ ), ageusia (with $\mathrm{RS}=54.6 \%$, without $\mathrm{RS}=$ $45.4 \%, p<0.001$ ), and myalgia (with $\mathrm{RS}=54.4 \%$, without $\mathrm{RS}=45.6 \%, p<0.001)$. The frequency of RS was also higher with patients who had four combined main neurological symptoms (headache, smell impairment, taste impairment, and myalgia) $(p<0.001)$ (Fig. 2).

\section{Risk factors associated with neurological symptoms}

- Univariate analysis showed that local transmission ( $p=$ $0.001)$, fever $(p<0.001)$, RS $(p<0.001)$, and gastrointestinal symptoms $(p<0.001)$ were associated with neurological symptoms.

- $\quad$ On a multivariate analysis, RS (OR = 3.162, CI: [1.3977.157], $p=0.006)$ and gastrointestinal symptoms (OR = 3.802, CI: [1.446-9.996], $p=0.007$ ) were independent predictive factors for the presence of neurological symptoms (Table 3).

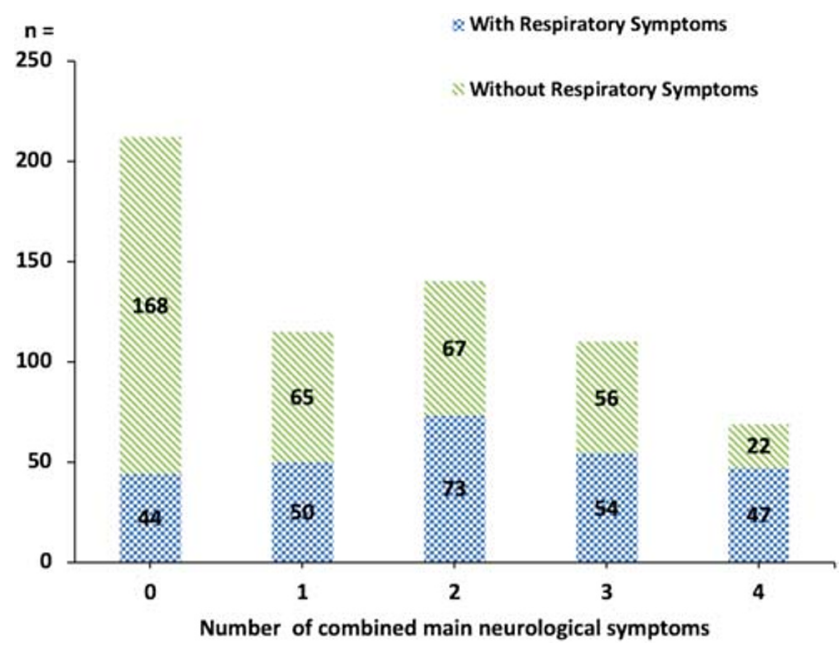

Fig. 2 Respiratory symptoms according to the combination of main neurological symptoms 
Table 3 Multiple logistic regression evaluating risk factors for COVID19 neurological symptoms

\begin{tabular}{llll}
\hline Variable & OR & CI 95\% & $p$ value \\
\hline Respiratory symptoms & 3.162 & $1.397-7.157$ & 0.006 \\
Gastrointestinal symptoms & 3.802 & $1.446-9.996$ & 0.007 \\
\hline
\end{tabular}

OR, odds ratio; $\mathrm{CI}$, confidence interval

Significant results have been italicized

\section{Discussion}

This study shows the prevalence of neurological manifestations in COVID-19 occurs in $72.1 \%$ of participants. In previous studies, neurological symptoms were noted in 13.9 to $57.4 \%$ of the cases $[9,11,12]$ and up to $84 \%$ in a series of patients hospitalized in intensive care units [10]. Headache, chemosensory impairment, and myalgia were the most frequently observed neurological symptoms in our series. Neurological symptoms preceded RS in $14.5 \%$ of the cases and were the sole presenting symptom in $22.7 \%$ of the cases. Interestingly, fever and cough were found in only one-third of the cases.

The high prevalence of COVID-19 neurological symptoms raises the question of a potential neurotropism and neurovirulence of SARS-CoV-2, as seen with other naturally neurotropic human coronaviruses. This is supported by autopsy reports of deceased COVID-19 patients where cerebral edema and reactive gliosis reported [9, 13]. Additionally, SARS-CoV-2 ribonucleic acid (RNA) has been detected in cerebrospinal fluid of patients with encephalitis [14].

In our study, headache was the most frequent neurological symptom (41.1\% of the cases). It was also reported as one of the most common complaints in participants with COVID-19 in several other studies where its prevalence ranged between 11.7 and $64.8 \%$ of the cases $[9,11,15]$. As yet, a detailed description of headache characteristics and timeline of its occurrence compared to other COVID-19 symptoms have not been undertaken. We have therefore emphasized here the early onset of this symptom and its main characteristics: a moderate intensity, a frontotemporal or generalized pain location, and a mean total duration of 4 days. Headache was not necessarily associated with fever. While a minority of headaches with COVID-19 are explained by meningitis/meningoencephalitis and or vascular events associated with COVID-19 hyper-coagulability [16], less is known about pathophysiological connection of isolated headache in COVID-19. Potential mechanisms include a cytokine-mediated immune injury, hypoxic injury, and ACE2 receptor saturation [8]. This could explain the occurrence of other COVID-19 neurological manifestations such as "toxic encephalopathies" [8] and confusion, seen in 13 participants within our series and up to $40 \%$ of the cases within the literature [10].
Chemosensory impairment was the second most frequently observed symptom within our study, with $37.9 \%$ and $36.8 \%$ of participants reporting smell and taste impairment respectively. Previous studies reported very variable rates ranging from 0.21 to $85.6 \%$ for smell impairment and from 0.23 to $88.0 \%$ for taste impairment [9, 11, 17-20]. Chemosensory impairment occurred early in the illness (in keeping with previous studies), with a complete anosmia or ageusia predominating and the majority of patients reporting complete recovery within less than 10 days [17]. The literature reports the higher prevalence of these symptoms compared to other respiratory viruses (influenza virus, parainfluenza virus, respiratory syncytial virus, coxsackievirus, adenovirus, poliovirus, enterovirus, and herpesvirus) [21]. In addition, contrarily to influenza, COVID-19 anosmia is typically not associated with nasal obstruction. Given the complete recovery within few days, the underlying pathophysiological mechanism is likely to be a destruction of the rapidly regenerating olfactory neuroepithelium (multipotent globose basal cells of the olfactory epithelium are active in giving rise to neurons for at least the first few days after a lesion and neurons reappear after 3-4 days after lesion and mature after 8-10 days after lesion [22]). The hypothesis of an altered neurotransmission by direct contact between SARS-CoV-2 and chemosensory receptors without cell destruction has also been suggested [23] and is strengthened by the fluctuating aspect of chemosensory impairment, seen in $29.9 \%$ of the cases in our cohort. Finally, central nervous system involvement is a possible etiology for anosmia in COVID-19 patients and may be explained by the presence of olfactory bulb edema on brain MRI [24] and cortical FLAIR hyperintensity in the gyrus rectus that resolves after 28 days [25]. This may explain the presence of olfactory hallucinations reported in $10.9 \%$ of our participants.

Regarding the other neurological symptoms, we noted a higher range of sleep disturbances, associated with anxiety in particular. A potential pathophysiological mechanism is reduced melatonin levels caused by societal "lockdown" and the resultant decrease in exposure to natural light, and therefore poor quality of sleep [26]. The effect of COVID-19 stress on sleep quality could also be incriminated.

Neurological emergencies were not found in our study but have been described in previous reports. New onset cerebrovascular disease has indeed been reported in $5 \%$ of the cases in a large Chinese cohort [9] and in five and six cases of series of patients in the USA and the UK [27, 28]. Neuroinflammatory immune-mediated syndromes including Guillain-Barré syndromes [29-32] and myelitis [33] have been documented. Finally, cognitive complaint, which was reported in five of our patients, has also been reported in a French cohort [10] where a dysexecutive syndrome was noted in $36 \%$ of the cases. The underlying mechanism is still unclear but a potential neurodegeneration is being proposed [34]. 
Two important observations of COVID-19 influencing factors can be drawn in our study. First, neurological symptoms were more frequently observed in patients with RS and the combination of several neurological symptoms was associated with greater respiratory involvement. Moreover, hospitalized patients had a higher frequency of neurological symptoms. This indicates a probable link between the severity of the disease and particularly of RS and neurological implications, as previously described [9]. Secondly, patients who contracted the virus abroad had a higher prevalence of neurological symptoms when compared to those who were infected locally. The differences of neurological and extra-neurological symptoms found in our population compared to other populations but also between imported cases and locally infected cases in Tunisia, suggest a possible less virulent "Tunisian" strain or a lower viral load. Indeed, the increasing diversification of SARS-CoV-2 strains has already been underlined - the complete genome sequencing of SARS-CoV-2 strains isolated in Asia, Europe, North, and South America identified 3 different genetic clades [35]. In Indian and Egyptian genetic studies, several mutations were recorded but the isolated SARS-CoV2 strains were at least $99.7 \%$ identical to $2019-\mathrm{nCoV}$-WHU01 strain $[36,37]$. Thus, the real implication in the pathogenicity remains to be confirmed.

Thus, neurological symptoms in COVID-19 are frequent, can be the initial signs, or occur sometimes in isolation. The main neurological symptoms are moderate headache, complete transient chemosensory impairment, and myalgia. Neurological symptoms were greater in imported cases and in patients with RS.

The present study has both strengths and weaknesses. The strengths of our study are the large population (more than a 1000 positive RT-PCR), the national scale including all people exposed to COVID-19 whether symptomatic/benign or not, and the fact that it is the first African study describing detailed characteristics and evolution of neurological COVID19 symptoms. The limitation of this study is the missing data due to the retrospective aspect of the study and the lack of neurological examination and brain imaging. Further studies are needed to confirm our conclusions.

Acknowledgments We would like to express our gratitude to the patients and all the colleagues who collaborated for the data collection, technical assistance, and review of the manuscript.

Authors' contributions The study design and conception were performed by KACEM Imen, HARIZI Chahida, NASRI Amina, MRABET Saloua, BEN DJEBARA Mouna, GARGOURI Amina, BEN ALAYA Nissaf, and GOUIDER Riadh. The draft of the manuscript was written by KACEM Imen and GHARBI Alya. NASRI Amina, MRABET Saloua, BEN DJEBARA Mouna, GARGOURI Amina, CHAHED Mohamed, BEN ALAYA Nissaf, and GOUIDER Riadh revised the manuscript. Data collection was performed by GHARBI Alya, SOUISSI Emira, SAFER Mouna, LETAIEF Hajer, AKKARI Manel, HECHAICHI Aicha, DHAOUADI Sonia, and DEROUICHE Sondes. The statistical analysis was made by HARIZI Chahida. All authors read and approved the final manuscript.

Data availability The data that support the findings of this study are available from the corresponding author upon reasonable request.

This paper has not been published before.

\section{Compliance with ethical standards}

Conflict of interest KACEM Imen, GHARBI Alya, HARIZI Chahida, SOUISSI Emira, SAFER Mouna, NASRI Amina, LETAIEF Hajer, AKKARI Manel, HECHAICHI Aicha, MRABET Saloua, DHAOUADI Sonia, BEN DJEBARA Mouna, DEROUICHE Sondes, GARGOURI Amina, CHAHED Mohamed, BEN ALAYA Nissaf, and GOUIDER Riadh declared that they have no conflict of interest relevant to the manuscript.

Ethics approval The protocol was approved by the local ethics committee of Razi Hospital, and the research was conducted in accordance with the 1964 Declaration of Helsinki.

Consent to participate Verbal informed consent to participate was obtained from all patients or their legal proxy prior to the interview

\section{References}

1. Walls AC, Park Y-J, Tortorici MA, Wall A, McGuire AT, Veesler D (2020) Structure, function, and antigenicity of the SARS-CoV-2 spike glycoprotein. Cell. https://doi.org/10.1016/j.cell.2020.02.058

2. Salata C, Calistri A, Parolin C, Palù G (2019) Coronaviruses: a paradigm of new emerging zoonotic diseases. Pathog Dis. https:// doi.org/10.1093/femspd/ftaa006

3. Chakroun H, Lasfar NB, Fall S et al (2020) Premier cas confirmé de COVID-19 importé en Tunisie First case of imported and confirmed COVID-19 in Tunisia. Tunis Med 98(4):258-260

4. Handrick S, Bestehorn-Willmann M, Eckstein S, Walter MC, Antwerpen MH, Naija H, Stoecker K, Wölfel R, Ben Moussa M (2020) Whole genome sequencing and phylogenetic classification of Tunisian SARS-CoV-2 strains from patients of the Military Hospital in Tunis. Virus Genes 1-5. https://doi.org/10.1007/ s11262-020-01795-9

5. Laamarti M, Kartti S, Alouane T et al (2020) Genetic analysis of SARS-CoV-2 strains collected from North Africa: viral origins and mutational spectrum. bioRxiv. https://doi.org/10.1101/2020.06.30. 181123

6. Louhaichi S, Allouche A, Baili H et al (2020) Caractéristiques des patients hospitalisés en pneumologie pour une infection COVID19: Première série Tunisienne Features of patients with 2019 novel coronavirus admitted in a pneumology department: the first retrospective Tunisian case series. Tunis Med 98(4):261-265

7. Vonck K, Garrez I, De Herdt V, Hemelsoet D, Laureys G, Raedt R, Boon P (2020) Neurological manifestations and neuro-invasive mechanisms of the severe acute respiratory syndrome coronavirus type 2. Eur J Neurol 27(8):1578-1587. https://doi.org/10.1111/ene. 14329

8. Wu Y, Xu X, Chen Z, Duan J, Hashimoto K, Yang L, Liu C, Yang C (2020) Nervous system involvement after infection with COVID19 and other coronaviruses. Brain Behav Immun 87:18-22. https:// doi.org/10.1016/j.bbi.2020.03.031

9. Mao L, Jin H, Wang M et al (2020) Neurologic manifestations of hospitalized patients with coronavirus disease 2019 in Wuhan, 
China. JAMA Neurol. https://doi.org/10.1001/jamaneurol.2020. 1127

10. Helms J, Kremer S, Merdji H et al (2020) Neurologic features in severe SARS-CoV-2 infection. N Engl J Med 382(23):2268-2270. https://doi.org/10.1056/NEJMc2008597

11. Daou BJ, Koduri S, Palmateer G, Thompson BG, Chaudhary N, Gemmete JJ, Pandey AS (2020) Letter: Neurological implications of COVID-19 and lessons learned from prior epidemics and pandemics. Neurosurgery 87(2):E234-E238. https://doi.org/10.1093/ neuros/nyaa186

12. Romero-Sánchez CM, Díaz-Maroto I, Fernández-Díaz E et al (2020) Neurologic manifestations in hospitalized patients with COVID-19: the ALBACOVID registry. Neurology. https://doi. org/10.1212/WNL.0000000000009937

13. Duarte-Neto AN, Monteiro RA de A, Silva LFF da, et al Pulmonary and systemic involvement of COVID-19 assessed by ultrasoundguided minimally invasive autopsy. Histopathology. https://doi. org/10.1111/his.14160

14. Huang YH, Jiang D, Huang JT (2020) SARS-CoV-2 detected in cerebrospinal fluid by PCR in a case of COVID-19 encephalitis. Brain Behav Immun. https://doi.org/10.1016/j.bbi.2020.05.012

15. Rodriguez-Morales AJ, Rodriguez-Morales AG, Méndez CA, Hernández-Botero S (2020) Tracing new clinical manifestations in patients with COVID-19 in Chile and its potential relationship with the SARS-CoV-2 divergence. Curr Trop Med Rep. https://doi. org/10.1007/s40475-020-00205-2

16. Montalvan V, Lee J, Bueso T, De Toledo J, Rivas K (2020) Neurological manifestations of COVID-19 and other coronavirus infections: a systematic review. Clin Neurol Neurosurg 194: 105921. https://doi.org/10.1016/j.clineuro.2020.105921

17. Beltrán-Corbellini Á, Chico-García JL, Martínez-Poles J et al (2020) Acute-onset smell and taste disorders in the context of COVID-19: a pilot multicentre polymerase chain reaction based case-control study. Eur J Neurol. https://doi.org/10.1111/ene. 14273

18. Yan CH, Faraji F, Prajapati DP, Boone CE, DeConde AS (2020) Association of chemosensory dysfunction and COVID-19 in patients presenting with influenza-like symptoms. Int Forum Allergy Rhinol. https://doi.org/10.1002/alr.22579

19. Moein ST, Hashemian SMR, Mansourafshar B, Khorram-Tousi A, Tabarsi P, Doty RL (2020) Smell dysfunction: a biomarker for COVID-19. Int Forum Allergy Rhinol 10(8):944-950. https://doi. org/10.1002/alr.22587

20. Lechien JR, Chiesa-Estomba CM, De Siati DR et al (2020) Olfactory and gustatory dysfunctions as a clinical presentation of mild-to-moderate forms of the coronavirus disease (COVID-19): a multicenter European study. Eur Arch Otorhinolaryngol 277(8): 2251-2261. https://doi.org/10.1007/s00405-020-05965-1

21. Welge-Lüssen A, Wolfensberger M (2006) Olfactory disorders following upper respiratory tract infections. In: Hummel T, WelgeLüssen A (eds) Adv. Otorhinolaryngol. KARGER, Basel, pp 125-132. https://doi.org/10.1159/000093758

22. Schwob JE (2002) Neural regeneration and the peripheral olfactory system. Anat Rec 269:33-49. https://doi.org/10.1002/ar.10047

23. Finsterer J, Stollberger C (2020) Causes of hypogeusia/hyposmia in SARS-CoV2 infected patients. J Med Virol. https://doi.org/10. 1002/jmv.25903
24. Laurendon T, Radulesco T, Mugnier J, Gérault M, Chagnaud C, El Ahmadi A-A, Varoquaux A (2020) Bilateral transient olfactory bulbs edema during COVID-19-related anosmia. Neurology https://doi.org/10.1212/WNL.0000000000009850

25. Politi LS, Salsano E, Grimaldi M (2020) Magnetic resonance imaging alteration of the brain in a patient with coronavirus disease 2019 (COVID-19) and anosmia. JAMA Neurol. https://doi.org/10. 1001/jamaneurol.2020.2125

26. Zambrelli E, Canevini M, Gambini O, D'Agostino A (2020) Delirium and sleep disturbances in COVID-19: a possible role for melatonin in hospitalized patients? Sleep Med 70:111. https:// doi.org/10.1016/j.sleep.2020.04.006

27. Avula A, Nalleballe K, Narula N, Sapozhnikov S, Dandu V, Toom S, Glaser A, Elsayegh D (2020) COVID-19 presenting as stroke. Brain Behav Immun 87:115-119. https://doi.org/10.1016/j.bbi. 2020.04.077

28. Beyrouti R, Adams ME, Benjamin L et al (2020) Characteristics of ischaemic stroke associated with COVID-19. J Neurol Neurosurg Psychiatry 91(8):889-891. https://doi.org/10.1136/jnnp-2020323586

29. Virani A, Rabold E, Hanson T, Haag A, Elrufay R, Cheema T, Balaan M, Bhanot N (2020) Guillain-Barré syndrome associated with SARS-CoV-2 infection. IDCases 20:e00771. https://doi.org/ 10.1016/j.idcr.2020.e00771

30. Scheidl E, Canseco DD, Hadji-Naumov A, Bereznai B (2020) GUILlAIN-BARRE syndrome during SARS-CoV-2 pandemic: a case report and review of recent literature. J Peripher Nerv Syst 25(2): 204-207. https://doi.org/10.1111/jns. 12382

31. Toscano G, Palmerini F, Ravaglia S et al (2020) Guillain-Barré syndrome associated with SARS-CoV-2. N Engl J Med 382(26): 2574-2576. https://doi.org/10.1056/NEJMc2009191

32. Padroni M, Mastrangelo V, Asioli GM, Pavolucci L, AbuRumeileh S, Piscaglia MG, Querzani P, Callegarini C, Foschi M (2020) Guillain-Barré syndrome following COVID-19: new infection, old complication? J Neurol. https://doi.org/10.1007/s00415020-09849-6

33. Munz M, Wessendorf S, Koretsis G, Tewald F, Baegi R, Krämer S, Geissler M, Reinhard M (2020) Acute transverse myelitis after COVID-19 pneumonia. J Neurol:1-2. https://doi.org/10.1007/ s00415-020-09934-w

34. Hascup ER, Hascup KN (2020) Does SARS-CoV-2 infection cause chronic neurological complications? GeroScience. https://doi.org/ 10.1007/s11357-020-00207-y

35. Castells M, Lopez-Tort F, Colina R, Cristina J Evidence of increasing diversification of emerging SARS-CoV-2 strains. J Med Virol. https://doi.org/10.1002/jmv.26018

36. Kandeil A, Mostafa A, El-Shesheny R et al (2020) Codingcomplete genome sequences of two SARS-CoV-2 isolates from Egypt. Microbiol Resour Announc 9:e00489-e00420

37. Potdar V, Cherian SS, Deshpande GR et al (2020) Genomic analysis of SARS-CoV-2 strains among Indians returning from Italy, Iran \& China, \& Italian tourists in India. Indian J Med Res 151:255260. https://doi.org/10.4103/ijmr.IJMR_1058_20

Publisher's note Springer Nature remains neutral with regard to jurisdictional claims in published maps and institutional affiliations. 